\title{
GASTOS MILITARES E AS AÇÕES DAS FORÇAS ARMADAS NA AMÉRICA DO SUL: UMA APRECIACCÃO SOBRE A CONVERGÊNCIA REGIONAL EM DEFESA
}

\author{
Graciela De Conti Pagliari'
}

\section{Introdução}

Passada quase uma década da formação do Conselho de Defesa (CDS) sob os auspícios da Unasul já é possível observá-lo a partir de sua condição formadora e ponderar os impactos desse arranjo entre os países da região. Vários estudos (Villa 20I7a, 20I7b; Nolte 20I8) vêm sendo feitos no sentido de ponderar acerca da institucionalização regional e a regular tendência à manutenção de crises militares e políticas. O CDS foi criado com o intuito de "implementar políticas de defesa em matéria de cooperação militar, ações humanitárias e operações de paz, indústria e tecnologia de Defesa, formação e capacitação"2. A dimensão da defesa, portanto, é o elemento norteador das ações do Conselho e para a qual o mesmo foi proposto como uma instância de consulta, cooperação e coordenação.

Considerando-se os seus principais objetivos como sendo consolidar uma zona de paz sul-americana, construir uma visão comum em matéria de defesa e gerar consensos para fortalecer a cooperação regional nesta área, o que este artigo se propõe a analisar é o CDS e sua capacidade de arregimentação regional em matéria de defesa. Ou seja, se a criação do CDS reduziu os custos das transações regionais na medida em que permitiu uma maior

I Professora de Relações Internacionais da Universidade Federal de Santa Catarina. Mestre pela Universidade Federal do Rio Grande do Sul. Doutora pela Universidade de Brasília. E-mail: graciela.pagliari@gmail.com

2 Apresentação e objetivos elencados na página inicial do sítio do CDS. Disponível em http://www. unasursg.org/es/consejo-defensa-suramericano. Acesso em I2 junho 20I7. Tradução nossa. 
Gastos militares e as ações das Forças Armadas na América do Sul: uma apreciação sobre a convergência regional em defesa

institucionalização da cooperação regional.

Quando da formação do CDS, o Brasil foi país ativo na busca do consenso regional para a sua criação. A conjuntura apresentava condições propícias para um maior desenvolvimento da institucionalidade regional - o que foi percebido e usado como ativo pelo governo do presidente Lula -, que se valeu dessa condição para congregar os países sul-americanos nesta nova empreitada regional. A ocasião parecia indicar que a não participação dos Estados Unidos no órgão recém-criado revelava um escopo positivo na construção de uma região que apresentava claramente preocupações sobre os mesmos temas de segurança, mas que ainda não havia construído conjuntamente proposições de respostas pois esbarrava em disparidades essencialmente sobre militarizá-las ou não.

A pouca capacidade de ação dos mecanismos hemisféricos em relação aos problemas que a América do Sul apresentava, bem como o foco dos Estados Unidos para outras regiões do mundo33, associavam-se a um período positivo de crescimento econômico e diminuição das instabilidades políticas regionais. Mas esse limiar entre estabilidade regional e instabilidades internas pode ser visto com uma condição verdadeiramente cambiante na América do Sul.

O propalado anel de paz ${ }^{4}$ não se sustenta como uma imagem da situação na região, o que pode ser destacado em importantes - mas não exaustivos exemplos: desde 200I o Plano Colômbia foi empregado para pôr fim à guerrilha cujo movimento contestatário desafiava a instabilidade das instituições colombianas; em 2006 ocorreu a crise da Media Luna na Bolívia5, com a Unasul com papel de destaque nessa concertação; em 2008 a invasão das forças armadas colombianas ao território equatoriano põe em destaque as rivalida-

3 Cepik (2009, 76-77) aponta que os focos de insegurança na região são de origem predominantemente doméstica, que os Estados Unidos - mesmo que focados especialmente na agenda de combate ao terrorismo - não descuidam de sua condição de hegemon regional. Além disso, o autor, olhando o quadro geral do complexo de segurança da América do Sul naquele período, aponta para um momento de avanço no desenvolvimento de "uma crescente institucionalização dos processos de solução de controvérsias por meio de uma multiplicidade de organizações, tais como a Organização do Tratado de Cooperação Amazônica (OTCA), Mercosul, Comunidade Andina (CAN) e, como desafio principal, a União da América do Sul (Unasur)". 4 Em discurso na cerimônia de anúncio da política de defesa nacional em o7 de novembro de I996, o então presidente Fernando Henrique Cardoso é assertivo ao afirmar que "A prioridade que o Governo vem dando à estabilização da economia e ao atendimento dos programas sociais, sem atender plenamente às necessidades de reequipamento dos órgãos de defesa, deve-se, em grande parte, ao verdadeiro anel de paz construído em torno do País". 5 Citando o exemplo de Media Luna, Serbin (2009) destaca a estratégia do Brasil de enfrentar as turbulências à estabilidade regional. 
des históricas no arco andino - a Operação Fênix extrapola a disputa bilateral especialmente porque as consequências indicam uma tensão crescente e uma securitização da região; em 2015 militares venezuelanos, em uma aparente emboscada, foram atacados em San Antonio del Táchira, o que levou ao fechamento da fronteira pelo governo venezuelano, precarizando ainda mais as já frágeis relações entre ambos os países.

No que tange ao sistema internacional, o momento apontava para um cenário no qual as potências intermediárias desfrutavam de uma capacidade de ação mais ampla do que era possível nas décadas da Guerra Fria, o que especialmente foi destaque na América do Sul uma vez que a região está apartada dos principais teatros de operações e a superpotência remanescente desenvolveu um baixo perfil de atuação nesta área.

A reatividade da criação da Unasul pende o tênue limiar conflito-cooperação para o segundo caminho quando, em resposta à invasão colombiana ao território do Equador, a Unasul e, posteriormente, o CDS entram em cena. A multilateralidade provocada pela Unasul coloca em outro patamar as relações regionais eis que conforma um cenário favorável para aproximação e para o desenvolvimento de cooperação multilateral em temas de defesa, tradicionalmente relegados a bi ou trilateralidade.

A atuação internacional mais assertiva do Brasil naquele momento destaca ainda mais o papel que Buzan e Waever (2003) colocaram para o Brasil como país-elo entre o norte e o sul da região, aquele que, por suas dinâmicas - seja no Cone Sul ou no norte andino - fazia com que o CRS da América do Sul se mantivesse como um só, em que pese duas sub-regiões de segurança. Assim, nada mais natural do que assumir papel decisivo no processo de aproximação que mirava a defesa regional, mas alcançava também a projeção internacional do país de modo mais amplo.

A proatividade destacada por Villa e Viana (20I0) e a assertividade definida por Soares de Lima (20I0) são demonstradas em questões como a mediação com a Turquia em relação ao programa nuclear iraniano ${ }^{6}$, a formação do documento da Estratégia Nacional de Defesa (2008), mas também, pela liderança na proposição da Unasul e do CDS. A formação de um Conselho de Defesa para fortalecer o diálogo e consenso em matéria de defesa mediante o fomento de medidas de confiança e transparência e visando promover a redução das assimetrias entre os sistemas de defesa dos Estados membros7 e

6 Gerou a Declaração de Teerã, em 20Io, entre Irã, Turquia e Brasil.

7 Conforme Estatuto Consultivo do Conselho de Defesa Sul-americano, item II - princípios, artigo 3, incisos d e i. 
com um processo decisório definido por consenso ${ }^{8}$, é uma criação sem precedentes no que tange à cooperação e à coordenação em matéria de defesa sul-americana. Solidificar as convergências permitiria aproximação no que tange à defesa, o que poderia reduzir as disparidades geradoras das crises regionais.

Assim, o intento deste trabalho reside em avaliar se a cooperação proposta pelo CDS segue na direção positiva de sua implementação. Metodologicamente o trabalho abordará o desenvolvimento da cooperação em defesa por meio das medidas de fortalecimento da confiança, especialmente em relação aos gastos militares e das missões atribuídas às forças armadas. Ambas variáveis permitirão enfocar especialmente em uma das quatro ações propostas pelo CDS no que diz respeito à implementação de políticas de defesa em matéria de cooperação militar. A primeira se justifica porque a promoção do diálogo e do consenso em matéria de defesa mediante o incremento de medidas de confiança e transparência é um dos objetivos do CDS; e a segunda, porque também tem o propósito de reduzir as assimetrias entre os sistemas de defesa dos Estados membros. Pois o sentido de missão das forças é um fundamento importante para analisar o avanço na cooperação em defesa, na medida em que se parte do pressuposto de que os temas de segurança que a região enfrenta refletiram em expectativas diferentes sobre qual deveria ser o papel das forças armadas no combate a tais ameaças.

O texto está dividido em uma seção introdutória de apresentação da discussão, uma a segunda seção que faz uma análise sobre os gastos militares e as medidas de confiança adensadas via CDS como forma de, por um lado, minimizar a possibilidade de dilemas de segurança e, de outro, de produzir uma instância regional de defesa. No terceiro segmento observa-se as atribuições das forças armadas da região no período pós-Guerra Fria com o intuito de observar se as divergências em segurança estão sendo dirimidas pelas ações adotadas a partir do CDS, visto que esse é um empecilho a ser superado. As considerações finais intentam retomar os pontos trabalhados para observar se os consensos avançaram em detrimento das divergências. Quer dizer, se os custos da institucionalização regional em defesa foram sendo superados via CDS a fim de que se possa testar a hipótese que considera que os países sul-americanos somente tendem a aproximação na medida em que os seus custos estão menos atrelados à mudança de suas políticas individuais tendendo, portanto, a consensos superficiais em detrimento da adoção e incorporação de políticas conjuntas.

Durante o coquetel, Zuma pareceu bastante satisfeito com a sua vida, mas dificilmente foi sincero na sua expressão. Sua saída do Estado levantou

8 Conforme artigo I3, do Estatuto Consultivo.

44 Austral: Revista Brasileira de Estratégia e Relações Internacionais v.7, n.14, Jul./Dez. 2018 
os freios às instituições legais da África do Sul, que logo entraram em ação. Já em 6 de abril Zuma foi indiciado com I 6 acusações que incluíam fraude, corrupção e extorsão, na Suprema Corte de Durban (Times Live 20ı8). Como antes, ele foi recebido por apoiadores que carregavam cartazes com os dizeres "Tirem as Mãos de Zuma" e "Iо०\% Inocente (ainda existem diversos destes na sua província natal) com sua canção favorita "Umshini Wami ([Traga-me] minha metralhadora)" (Daily Maverick 20I8). Mas desta vez a sorte dificilmente estará do seu lado. A próxima sessão da corte está marcada para 8 de junho, e o escritório do promotor listou 207 testemunhas (The South African 20I8). Até agora, Shabir Shaik, o qual foi libertado da prisão por "questões de saúde", após cumprir dois anos dos I5, não é uma delas, mas testemunhará no tribunal caso seja intimado (WN 20ı8). O quão forte serão suas evidências que são apresentadas pela mídia como potencialmente "explosivas" e quantos "homens bomba" se juntarão a ele? O que acontecerá com Jacob Zuma? Teremos que esperar pelas respostas finais e, dado o sistema legal sul-africano, isto provavelmente levará anos.

\section{Medida de fortalecimento da cooperação: gastos militares}

Essa seção trata de avaliar um ponto importante na construção de uma institucionalidade regional, que se assenta nos gastos militares e seus efeitos em termos de defesa regional. Em uma área que tradicionalmente foi marcada por demonstrações de força, mesmo que não guerra, os gastos militares e suas finalidades são essencialmente importantes.

A agenda regional deu atenção aos investimentos em medidas de fortalecimento da confiança ${ }^{9}$ para adensar a cooperação como forma de mitigar as desconfianças e, com isso, modificar as relações entre as díades e tríades visando mudar o cálculo dos atores de relações de tensão e conflitos tradicionais de fronteira e demonstrações de força, para distensões que permitiriam conformar relações de proximidade. Somente com elas é possível almejar a institucionalização regional em defesa. Ao agir desta maneira, os países acumulam um ativo na agenda regional que servirá para aumentar o grau de transparência e confiança necessário para concertar políticas de defesa.

Os gastos em defesa são uma boa medida para verificar se as ações em defesa vão gerar um dilema de segurança entre os Estados. Mesmo que os gastos sejam bastante menores na América Latina em geral do que nas

9 Uma discussão sobre as medidas de fortalecimento da confiança e seu uso na região pode ser vista em Rojas Aravena (I996); Flames (2005); e Saint-Pierre e Palacios Junior (20I4). 
outras regiões do mundo, as desconfianças e rivalidades se exacerbam em cada movimento de investimento militar. O Atlas Comparativo de la Defensa en América Latina y Caribe (2016), produzido pela RESDAL, apresenta os valores dos gastos em defesa na América Latina para o período 2006 a 2016, mostrando que a média do orçamento da região destinado a defesa foi de 3,7\% em relação ao orçamento do Estado. Este percentual não é insignificante, bem ao contrário. Por isso intentamos mostrar neste trabalho as destinações destes recursos e seus usos entre diferentes rubricas.

Optou-se por considerar as medidas de confiança como um indicador da aproximação e concertação entre os Estados, seguindo os objetivos traçados pelo CDS. A discussão sobre adoção de medidas de mensuração dos gastos militares se desenvolve no continente americano de maneira mais assertiva a partir de meados da década de I990. Um importante resultado dessas discussões foi alcançado na Conferência de Ministros da Defesa da Américas de 2004, quando se reiterou que "a transparência orçamentária é um fator fundamental da cooperação em matéria de segurança e defesa, para o que é propícia a implementação de metodologias de medição do gasto de defesa como um mecanismo ótimo de confiança mútua" (CEED 20I7, 58).

Em 2010, os países estabeleceram Procedimientos de Aplicación para las Medidas de Fomento de la Confianza y Seguridad o qual considera (I) o intercâmbio de informação e transparência com relação aos (A) sistemas em defesa e aos (B) gastos em defesa; bem como as referentes às (II) atividades intra e extra-regionais, além de (III) medidas em âmbito de segurança e (IV) garantias sobre a proscrição do uso da força, zona livre de armas nucleares, respeito ao direito internacional nos acordos de cooperação em matéria de defesa e garantia do não uso destes contra a soberania, segurança, estabilidade e integridade territorial dos membros; e (V) medidas de cumprimento e verificação que serão feitas mediante o mecanismo voluntário de visitas a instalações militares, programas de contatos e cooperação militar e a verificação das situações nas zonas de fronteira, que se desenvolverá com a colaboração de um organismo internacional.

Com relação mais especificamente aos gastos em defesa, concordaram em informá-los e, posteriormente, proceder a homologação das informações fornecidas e conformar um padrão para medição estandarizada destes gastos. O CEED passou a consolidar os dados dos gastos em defesa e, até o presente, lançou três documentos com as relativas informações: "Registro Sul-Americano de Gastos Agregados em Defesa (2006-2010)”, publicado em dezembro de 2014; "Registro Sul-Americano de Gastos Agregados em Defesa 20II-20I3”, publicado em maio de 20I6, e "Registo Sul-Americano de Gastos 
Agregados em Defesa 2006-2015", publicado em janeiro de 2017.

O estabelecimento de uma metodologia comum a partir de 20II para a medição dos gastos em defesa está estabelecida considerando uma definição dos gastos que inclui

todos os recursos alocados pelo Estado para financiar as atividades que compõem a segurança externa da Nação. Ela inclui também a ajuda externa recebida para esse efeito (monetária e não-monetária). Do ponto de vista institucional, isso significa considerar o gasto das Forças Armadas e suas agências, e todos os outros órgãos do setor público que têm como papel principal defender o país contra desafios externos (governo central mais entidades descentralizadas).

É excluído do conceito de gasto de defesa os realizados pelo Estado para proteger a sua segurança interna, inclusive se utiliza meios das Forças Armadas, ou seja, não são incluídos os gastos de polícia, gendarmeria, guarda costeira, órgãos de controle da aviação civil e controle da segurança marítima (CEED 20I7, 6I).

A metodologia adotada define os principais eixos de medição do Registro a (I) classificação por objeto de gasto e por agência de execução do mesmo e (II) diretrizes para o formato de apresentação da série. A instituição executora do gasto também foi classificada de modo independente e as mesmas são o Ministério da Defesa, o Comando Conjunto; o Exército; a Marinha; a Força Aérea; e, se aplicável, Outros.

Já em relação ao objeto, o gasto em defesa é assim dividido:

I) pessoal (remunerações);

2) operações e manutenção (bens de consumo e serviços);

3) investimentos (sistemas de armas, infraestrutura física e outros equipamentos);

4) pesquisa e desenvolvimento.

Ao longo do período com dados tabulados que se inicia em 2006 e vai até 20I5, pode-se observar um gasto regional em defesa como percentagem do PIB regional com uma média de $0,98 \%$, como se verifica no quadro abaixo. Como já destacado, esses valores são substancialmente abaixo da média mundial e pode ser um fator indicativo de que os países da região consideram pouco prováveis disputas entre atores estatais regionais ou extrarregionais. Mas também uma outra indicação que pode auxiliar a entender os percentuais de gastos militares é que, de maneira geral e ampla, os países da região possuem preocupação muito intensa com problemas 
Gastos militares e as ações das Forças Armadas na América do Sul: uma apreciação sobre a convergência regional em defesa

internos aos países, tais como altos índices de violência, e os dados apresentados não incluem os valores destinados à segurança pública via polícias civis e militares.

O desafio de conformar a região como uma zona de paz passa não apenas por gastos militares baixos, mas por relações de confiança de que os gastos - mesmo que em baixa quantidade - não são constituídos para ameaçar os demais países da região, seguindo na linha de rivalidades regionais consubstanciadas por meio de balanças de poder.

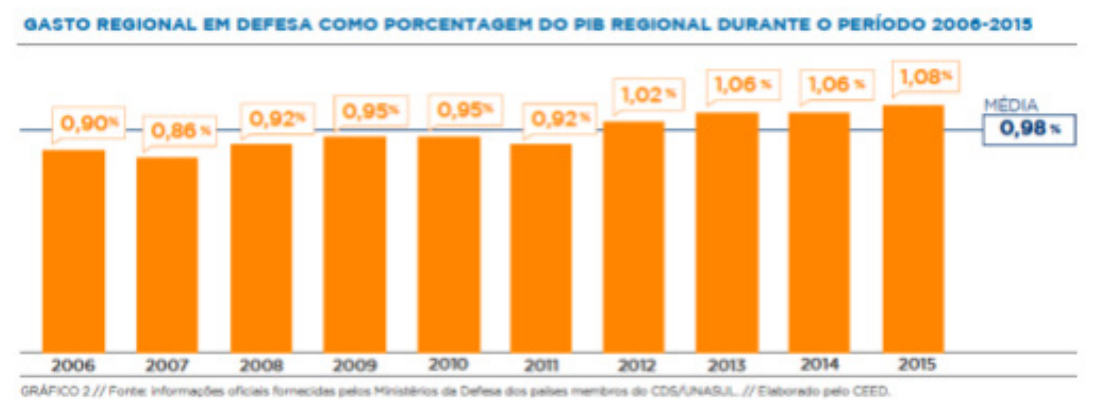

Se ao longo do período de 2006 a 2014 ocorreram crescimentos constantes em relação aos valores ${ }^{10}$ dos gastos militares, observa-se que no ano de 2015 há uma redução considerável (de mais de I4\%), retomando a patamares do início da década. Muitos fatores podem explicar tal redução como a crise econômica que assola vários Estados da região - crise que também refletiu na redução dos gastos militares de Europa e de EUA -; a crise política e instabilidade institucional em Brasil e Venezuela; a desmobilização das FARC na Colômbia que impacta na destinação dos valores de assistência militar dos EUA àquele país.

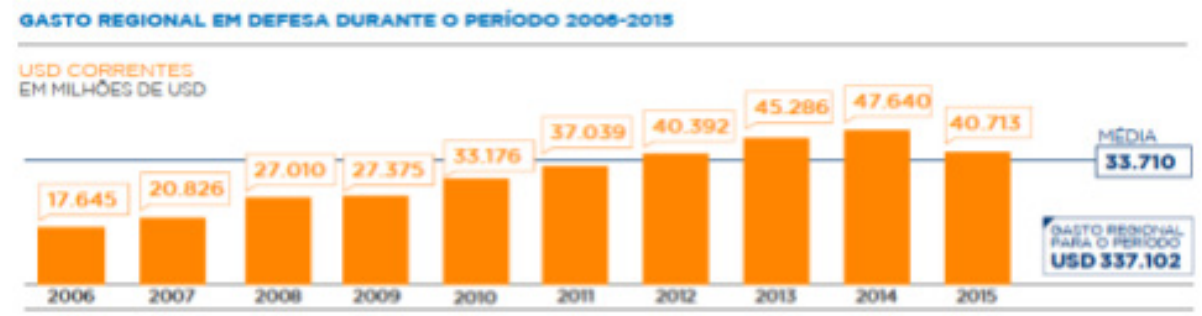

USD CONSTANTES CMMILHOES DSUS

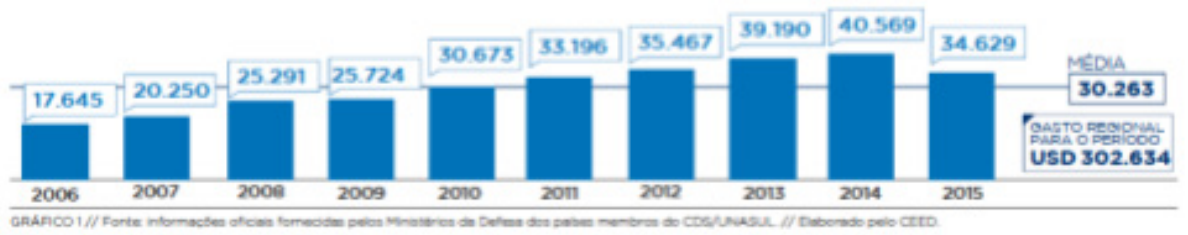

ıo Considerado em dólares.

48 Austral: Revista Brasileira de Estratégia e Relações Internacionais v.7, n.14, Jul./Dez. 2018 
Nos gastos consolidados em defesa percebe-se que os custos com pessoal representam a destinação de maior monta. Enquanto os gastos regionais em investimentos apresentam variações consideráveis ao longo do período, como será tratado adiante, os gastos com pessoal mantêm-se constantes, com uma tendência de alta pronunciada, variando de $62,76 \%$ em 2006 para $67,49 \%$ em 2015 .

Os investimentos aportam em uma média de I7,I $8 \%$ dos recursos, sendo o terceiro $^{\text {II }}$ objeto em gastos durante o período. Nesse item estão incluídos:

(I) sistema de armas - aquisição e modernização de equipamentos militares destinados à defesa, como carros de combate, veículos blindados de combate, sistemas de artilharia de grande calibre, aviões e helicópteros de combate, navios de guerra, mísseis e lança-mísseis, dentre outros;

(II) a infraestrutura física (que inclui o custo de construção de instalações e aquisições de bens móveis), e

(III) outros equipamentos como aquisição e modernização de veículos, aeronaves, navios de apoio logísticos, máquinas e equipamentos (de transporte, saúde, comunicações, informática...) e intangíveis (licenças, licenças especiais...).

\begin{tabular}{|c|c|c|c|c|}
\hline ANO & PESSOAL & $\begin{array}{l}\text { OPERAÇÃO E } \\
\text { MANUTENÇÃ̄O }\end{array}$ & INVESTIMENTOS & $\begin{array}{c}\text { PESQUISA E } \\
\text { DESENVOLVIMENTO }\end{array}$ \\
\hline 2006 & $62,76 \%$ & $22,80 \%$ & $13,58 \%$ & $0,35 \%$ \\
\hline 2007 & $57,91 \%$ & $23,83 \%$ & $17,61 \%$ & $0,33 \%$ \\
\hline 2008 & $55,89 \%$ & $23,15 \%$ & $20,18 \times$ & $0,61 \%$ \\
\hline 2009 & $58,46 \%$ & $24,17 \times$ & $16,48 \%$ & $0,72 \%$ \\
\hline 2010 & $57,31 \%$ & $23,38 \%$ & $18,40 \%$ & $0,75 \%$ \\
\hline 2011 & $61,34 \%$ & $23,63 \times$ & $14,51 \%$ & $0,43 \%$ \\
\hline 2012 & $56,53 \%$ & $21,60 \%$ & $21,54 \times$ & $0,23 \%$ \\
\hline 2013 & $57,03 \%$ & $21,14 \%$ & $21,57 \times$ & $0,17 \%$ \\
\hline 2014 & $60,96 \%$ & $20,88 \times$ & $17,72 \%$ & $0,35 \%$ \\
\hline 2015 & $67,49 \%$ & $21,44 \%$ & $10,19 \%$ & $0,77 \%$ \\
\hline MÉDIA & $59,57 \%$ & $22,60 \%$ & $17,18 \%$ & $0,47 \%$ \\
\hline
\end{tabular}

A pesquisa e desenvolvimento, por sua vez, apresenta percentuais inferiores a I\% do montante investido, conforme se observa no quadro acima. Ou seja, a ações essenciais para a obtenção de novos conhecimentos e/ou pesquisa de suas aplicações baseadas em iniciativas de desenvolvimento tecnológico, inovação para a produção

II Em primeiro lugar está o item pessoal, seguido dos percentuais de operação e manutenção. 
Gastos militares e as ações das Forças Armadas na América do Sul: uma apreciação sobre a convergência regional em defesa

para a defesa e geração de novos conhecimentos, fica relegada ao menor patamar dentre os destinos dos recursos.

Um dos percentuais importantes a serem analisados refere-se aos investimentos. Relativamente ao gasto em defesa constata-se uma queda em relação a esse percentual ao longo dos anos. Em 2006, o percentual na rubrica foi de I3,58\%; em 2013 foi o ano de maior percentual investido com 21,57\% e em 20I5, último ano dos dados consolidados, o percentual foi de Io,I9\%, totalizando uma média no período 2006-20I5 de I7,I8\%, demonstrando uma variação bastante importante em um período de uma década e meia de amostragem.

Como se pode ver no gráfico abaixo, as percentagens desagregadas em relação aos subcomponentes refletem essa mesma trajetória de variação. O sistema de armas apresenta um percentual de 5I,86\% em 2006 (seu mais alto percentual, inclusive) depois é reduzido a $25,36 \%$ em 2012 e finaliza 2015 com 33,21\%. Por outro lado, o subcomponente Outro Equipamento termina o período com uma tendência de alta. Em 2006 representa $36,99 \%$, em 2010 (o mais baixo percentual) fica em $33,33 \%$ e encerra 2015 com o percentual de $5 \mathrm{I}, 77 \%$.

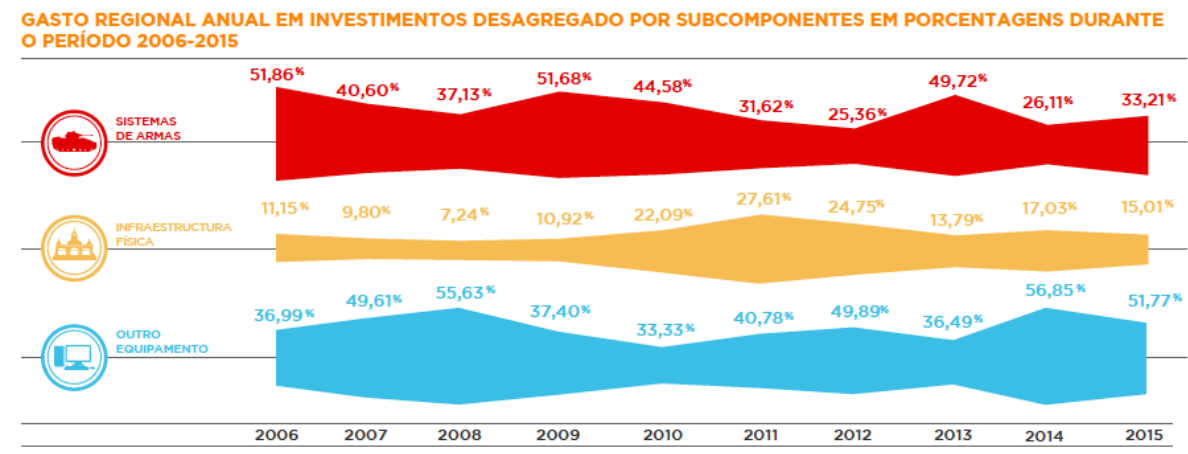

GRÁFICO 16 // Fonte: Informacces oficials fornecidas pelos Ministérios da Defesa dos paises membros do CDS/UNASUL // Elaborado pelo CEED.

Em uma primeira avaliação pode-se verificar uma inconstância de valores que demonstra como os países são suscetíveis a modificarem os valores dos gastos a partir das limitações/constrangimentos financeiros. Os projetos de longo prazo, como o caso dos sistemas de armas, necessitam de investimentos ao longo de vários anos até alcançarem a sua consolidação. Mesmo que percentualmente em termos de PIB os valores dos gastos militares regionais não apresentem grandes variações, nominalmente o impacto é significativo uma vez que o não crescimento do PIB ou sua queda representam redução nominal de investimentos. Outra significativa questão para se pensar a esse respeito é que após a ocorrência da invasão colombiana ao território equatoriano, em 2008, a região não apresentou mais nenhuma situação de securitização regionalizada significativa, mas isso não necessariamente deveria refletir de imediato pois o que se leva em conta aqui são projetos de longo prazo.

Atentando para os resultados que os relatórios em si representam, pode-se 
destacar algumas conclusões, especialmente com relação às unidades que mais gastos despendem

O Exército se destaca como a mais importante unidade de execução do gasto, dispendendo (sic) 42,48\% do gasto total regional da década; nesse âmbito, no entanto, desde o ano 2006 até 2014 registra-se um incremento superior ao 600\% na execução do gasto realizado pelos Ministérios da Defesa (CEED 20I7, 53).

Destaca também o ineditismo do desenho metodológico do registro de gastos em defesa, fator que demonstra a construção de confiança e transparência entre os Estados, uma vez que - após inúmeras reuniões e tratativas - os parâmetros de medição delineados, foram acordados. Verifica-se aqui um claro exemplo de concertação em temas de defesa, o que poderia demonstrar que o CDS apresenta condições de ser um mecanismo de governança regional efetivo, em que pese todas as divergências a serem superadas. O Relatório destaca que

Conforme as características do desenho metodológico, o Registro Sul-Americano de Gastos em Defesa é um instrumento inédito que não conta com paralelos a nível global. Com efeito, enquanto que os informes de gastos em defesa formulados por algumas das organizações internacionais (governamentais ou não governamentais) dedicadas à matéria se constroem com base em projeções orçamentarias, o Registro Sul-Americano se elabora sobre os gastos em defesa efetivamente executados por cada Estado Membro e oficialmente informados anualmente ao Conselho de Defesa Sul-Americano (CEED 20I7, 53).

A vontade política e o consenso que os membros da Unasul alcançaram em matéria de verificação dos gastos militares é destacado pelo CEED (Anexo 4, Informe Preliminar) no sentido de que a cooperação no setor de defesa respeita as diferenças e particularidades nacionais, mas também usa os elementos coincidentes para avançar nas complementaridades estratégicas. Nesse sentido, os custos atrelados a aproximação devem ir sendo reduzidos.

Não é possível apresentar maiores conclusões no que diz respeito aos valores em si no sentido de representatividade dos mesmos com relação a formação de balanças regionais uma vez que os dados se encontram integralizados para todos os países. Contudo, para fins 
desse artigo, pode-se dizer que o propósito de verificação dos gastos em defesa contribui para a construção da confiança na América do Sul.

$\mathrm{Na}$ seção a seguir, trata-se de ponderar acerca da aproximação em termos de defesa a partir da verificação das atribuições que os países designam para suas forças armadas. Espera-se com isso verificar se esse ponto de divergência também foi modificado para uma maior convergência temática e de missão.

\section{Atribuições das forças armadas no pós-Guerra Fria e seu pa- pel em defesa na América do Sul ${ }^{12}$}

América Latina de modo geral, e a América do Sul de modo particular, retornam aos regimes democráticos no período coincidente com os anos finais da Guerra Fria o que influencia sobremaneira as relações entre as forças armadas e os sistemas políticos. Assim, ao passo que a área sul-americana foi afetada pelas alterações sistêmicas, também mudanças internas à região e aos Estados se processaram, impactando de modo significativo tanto na expectativa do modo de atuação das forças armadas quanto nas preocupações de segurança e defesa da região.

A consolidação dos processos de democratização vai cristalizando as relações político-militares. E passa a produzir questionamentos tanto em relação aos investimentos militares quanto à necessidade de os Estados possuírem grandes aparatos dessa natureza. De acordo com a tendência ao militar pós-moderno depois da Guerra Fria, as forças armadas dos países e os tomadores de decisão vão se deparar com essa alteração que se processa em várias partes do mundo no sentido de atribuir aos militares tarefas que não são tradicionalmente suas, assim também colocá-los em missões internacionais sob os auspícios de organismos como ONU ou mesmo de atuações em organizações combinadas - como Eurocorps (Garcia 2002).

O que se desenha nesse período é a constituição de uma atmosfera de descrença ou quase impossibilidade de um conflito entre Estados nacionais. As forças armadas da região haviam perdido a função interna que desempenharam na bipolaridade e também se depararam com a ausência de um inimigo externo. Assim, tornava-se difícil justificar aparatos militares robustos. Mesmo tendo sido, tradicionalmente, uma das zonas mundiais que menos

\footnotetext{
I2 Uma versão preliminar dessa seção foi publicada no capítulo "Forças Armadas e sua importância para a região austral do Prata", no livro Fronteiras contemporâneas comparadas: relações internacionais e segurança regional no Brasil e na União Europeia, 20 б6.
} 
têm investido em termos militares, os questionamentos à destinação de recursos para as forças estiveram presentes, pautados em motivadores como mudanças políticas internas, ressentimentos e problemas econômicos (Aguilar 2008).

O período ditatorial anterior e a percepção da sociedade acerca das forças armadas, influenciaram grandemente tais questionamentos que também se assentavam na baixa ou escassa transparência dos processos de aquisições militares ${ }^{13}$. No imediato pós-Guerra Fria os investimentos militares passam por uma redução percentual em termos de PIB, conforme mostram os percentuais abaixo ${ }^{\mathrm{I} 4}$.

\begin{tabular}{lcccccc} 
& $\mathbf{1 9 8 8}$ & $\mathbf{1 9 8 9}$ & $\mathbf{1 9 9 0}$ & $\mathbf{1 9 9 1}$ & $\mathbf{1 9 9 2}$ & $\mathbf{1 9 9 3}$ \\
\hline Argentina & $2,0 \%$ & $1,8 \%$ & $1,4 \%$ & $1,4 \%$ & $1,3 \%$ & $1,3 \%$ \\
Brasil & $2,1 \%$ & $2,7 \%$ & $2,4 \%$ & $2,0 \%$ & $1,5 \%$ & $1,9 \%$ \\
Chile & $4,3 \%$ & $3,5 \%$ & $3,4 \%$ & $2,8 \%$ & $2,6 \%$ & $2,7 \%$ \\
Paraguai & - & $1,9 \%$ & $1,7 \%$ & $2,1 \%$ & $2,0 \%$ & $1,5 \%$ \\
Uruguai & $3,2 \%$ & $3,5 \%$ & $3,5 \%$ & $2,4 \%$ & $2,8 \%$ & $2,8 \%$ \\
Fonte: elaborado pela autora com base nos dados de SIPRI Military Ex- \\
penditure Database, 2015.
\end{tabular}

Com essa redução permite-se modificar a situação de desconfiança que se mantinha entre os países da região, bem como criam-se as condições para que as forças militares passem a participar de encontros conjuntos que são a base para os exercícios militares de fortalecimento de confiança entre os países do Cone Sul (Pagliari 2004).

De outra maneira, em que pese a pressão para a atuação nas chamadas novas ameaças, as forças armadas não incorporaram tal missão. Donadio

I3 A elaboração de Livros Brancos visa modificar esse cenário, mas veja-se que o Brasil apenas institui o seu LBDN em 20I2. Mesmo que anteriormente tenham sido criadas as Políticas Nacionais de Defesa e a Estratégia Nacional de Defesa, é o Livro Branco que representa o caráter de transparência nos assuntos de defesa e o avanço no processo de consolidação do poder civil sobre o militar. A atualização do LBDN publicado em 2012 foi elaborada em 2016 e encaminhada para apreciação do Congresso Nacional.

I4 A base de dados do SIPRI tanto usa os percentuais do PIB, quanto os valores em dólares atuais e constantes. Optou-se por utilizar a tabela embasada no PIB pois esses dados demonstram uma proporção em relação ao montante dos gastos do Estado, que nem sempre os valores em dólares permitem constatar pois aparecem isolados do todo. 
Gastos militares e as ações das Forças Armadas na América do Sul: uma apreciação sobre a convergência regional em defesa

(2003, 8 - tradução nossa) afirma que “....as forças armadas da região mantiveram-se em geral (com a óbvia exceção da Colômbia) apartadas de pressões para introduzirem-se em tarefas como a luta contra o narcotráfico" ${ }^{15}$. Se essa ação interna foi bastante combatida pelas próprias forças latino e sul-americanas, a proposta de emprego das mesmas em situações internacionais como capacetes azuis da ONU, não encontrou a mesma resistência. Ao contrário, os países passaram a destinar contingentes para essa preparação e atuação que passou a ser bastante constante a partir de então ${ }^{\mathrm{I} 6}$.

Diamint (2006) destaca que a democratização se desenhou com a tarefa central de retomar o controle das estruturas militares, mas, se esse propósito foi de certa maneira alcançado, o mesmo não se pode dizer em relação à organização racional e planejada da defesa. Apresenta a autora que

As falências na produção das políticas de segurança (considerando-se o termo em sua concepção ampliada), contradiz os esforços de fortalecimento do sistema democrático. Este déficit de condução e gestão se reforça pelo exponencial crescimento da insegurança pública, que produz uma eventual sobreposição entre as funções da defesa com as funções policiais, contrariando a necessária separação republicana entre defesa externa e ordem pública interna (Diamint 2006, 59 - tradução nossa) ${ }^{17}$.

Com um externo que se apresentava quase sem perspectivas de conflitos, mas com situações internas que mostravam um crescente desafio em termos de segurança pública com impacto cada vez maior no cotidiano de seus cidadãos, a região recorre às forças armadas como resposta institucional. Saint-Pierre e Donadelli $(2016,89)$ asseveram que

em alguns casos seja por deficiência institucional, por urgências de agenda eleitoral, por fadiga da democracia ou até mesmo por falta de preparo de civis para exercer a condução política nas áreas da segurança pública e da defesa, os governos da região foram, de forma mais contínua e em uma

\footnotetext{
I5 No original: “... las fuerzas armadas de la región se han mantenido en general (con la obvia excepción de Colombia) apartadas de presiones para introducirse en tareas tales como la lucha contra el narcotráfico".

I6 Os documentos de defesa brasileiros elaborados em 2016 ressaltam de maneira significativa a importância das atuações em missões de paz, com a intenção de seguir destinando contingentes para tal tarefa.

I7 No original: "Este déficit de condución y gestión se refuerza por el exponencial crecimiento de la inseguridad pública, que produce una eventual superposición entre las funciones de defensa con las funciones policiales, contrariando la necesaria separación republicana entre defensa externa y ordem público interno".
}

54 Austral: Revista Brasileira de Estratégia e Relações Internacionais v.7, n.14, Jul./Dez. 2018 
maior variedade de missões, recorrendo à suas Forças Armadas como única instituição disponível, eficiente e confiável. Em alguns casos, este emprego generalizado das Forças promove perigosas mudanças constitucionais para a sua legitimação; em outras, é promovido em clara desconformidade com os preceitos constitucionais, deixando aos militares cumprirem com essas funções num limbo jurídico e sem qualquer cobertura legal.

Nas jovens democracias da região é interessante observar como na maior parte delas (sendo a maior excepcionalidade a Argentina) as forças armadas são apontadas como a instituição vinculada ao Estado que mais gera confiança. O relatório de 2016 do Latinobarômetro mostra que a confiança nas instituições sofreu uma redução em relação ao período anterior, com exceção das forças armadas e da polícia, apresentando leves altas, esta passando de $36 \%$ para $38 \%$, e aquela de $66 \%$ para $69 \%$. A média da confiança das forças armadas no período I995-20I6 é de 47\%, sendo a instituição pública mais bem colocada em termos de confianç ${ }^{18}$. Essa demonstração de confiança não decorre de seu papel em guerras pois, como destaca o mesmo relatório "sem guerras, América Latina acusa violência, corrupção e a desigualdade como os fenômenos mais potentes que retêm a democracia ${ }^{19}$ " (Latinobarómetro 20I6, s/n - tradução nossa).

Contudo, em que pese a convergência regional sobre a intensificação da subordinação militar ao poder civili2。, nem os temas de segurança e defesa foram adequadamente definidos nem a questão de o que, de fato, permeia o interesse nacional dos países. Soares de Lima (2010, 409) destaca que "se o controle civil é uma das condições necessárias, não é suficiente, pois falta a definição política do Estado que estabeleça objetivos de sua autonomia no plano internacional".

Na América do Sul, considerando as previsões constitucionais, todos os países da região atribuem às forças armadas a defesa nacional, por outro lado, apenas Brasil, Colômbia e Bolívia, possuem como atribuição a garantia

I8 Por seu turno, os dados demonstram que a democracia apresenta dificuldades para se consolidar pois somente $22 \%$ (uma cifra em queda há vários anos) tem a percepção de que os seus governos governam para toda a população.

I9 "Sin guerras, América Latina acusa violência, corrupción y la desigualdad como los fenómenos mas potentes que retienen a la democracia".

20 Em descompasso com essa tendência de intensificação do tratamento da questão civil-militar, o LBDN do Brasil, na versão 2016 - em trâmite no Congresso Nacional - deixa de abordar essa relação. No documento anterior havia a declaração expressa "ressalte-se que a obediência das Forças Armadas ao poder político constitucional é pressuposto do regime republicano e garantia da integridade da Nação, estando sob a autoridade do Presidente da República, por intermédio do Ministério da Defesa" (LBDN 20I2, 56). 
da ordem constitucional. A garantia da ordem interna é atribuída constitucionalmente aos militares no Brasil, Peru e Venezuela, enquanto que a garantia da estabilidade governamental é atribuição constitucional nas constituições paraguaia e boliviana.

Tais previsibilidades de missão também podem ser definidas em leis complementares às constituições ${ }^{21}$, como é o caso da cooperação no que diz respeito à ordem (ou segurança interior). Nesse caso, observa-se que há a previsibilidade dessa atribuição em todos os Estados da região, exceto que, no caso da Argentina, esse papel somente se dá em situações de estado de exceção pois a sua atuação mantém-se voltada para o externo - seja ameaças tradicionais ou mesmo participação em operações de paz. Saint-Pierre e Donadelli (20I6, p. 94) apontam que as legislações sul-americanas referentes ao emprego militar que não referente à defesa nacional apresentam como previsibilidade de ações internas distintas nomenclaturas como "I.) Garantia da Ordem Constitucional/Estabilidade Governo Legal; 2.) Garantia da Ordem Interna/Segurança Interior; 3.) Participação no Desenvolvimento Nacional; 4.) Apoio a processos eleitorais e 5.) Apoio em caso de desastre".

Segundo dados do Atlas Comparativo de la Defensa en América Latina y Caribe (20I4), ao longo do tempo, o espectro de ações desenvolvidas pelas Forças Armadas foi sendo ampliado, além da manutenção da paz se incorporaram tarefas relacionadas inclusive com a cooperação em segurança pública. Naquele ano, 94\% dos países da região realizaram de maneira regular alguma atividade ou operação vinculada à segurança pública, seja de combate ao narcotráfico, patrulhas urbanas, controle permanente de fronteiras, segurança de grandes eventos e pacificação em zonas violentas. No Altas 20I6, os assuntos atinentes à segurança pública mantêm-se ressaltados dentro das situações relativas à segurança na região. A XII Conferência de Ministros de Defesa das Américas que teve lugar em Trinidad y Tobago, entre io a I2 de outubro de 2016 , o mote principal foi o fortalecimento da cooperação para defesa e a segurança no hemisfério em um entorno global cada vez mais volátil. Seus eixos temáticos giraram em torno da evolução da função das forças armadas, da proteção e capacidade de resposta aos problemas ambientais, e a cooperação e fortalecimento da assistência em emergência humanitária, seguindo-se, portanto, com a demonstração de preocupação com a segurança pública.

No que diz respeito às operações de fronteira, que são sempre destacadas e enfatizadas pelo Brasil ${ }^{22}$, são muito mais vinculadas a delitos como

2I Para uma análise mais precisa das legislações infraconstitucionais e das situações de emprego internamente das forças armadas nos países da América do Sul, ver Saint-Pierre e Donadelli (2016).

22 Em discurso na abertura da IIX Conferência de Ministros de Defesa das Américas (CMDA),

56 Austral: Revista Brasileira de Estratégia e Relações Internacionais v.7, n.14, Jul./Dez. 2018 
vigiar a fronteira para restringir a entrada de armas e munições, relacionadas com o tráfico de drogas e guerrilhas do que propriamente a eventuais ameaças que outros países possam provocar em termos de ameaças tradicionais de fronteira sobretudo porque na região as ameaças tradicionais estão latentes e não fortemente securitizadas. Como o tráfico de drogas é uma das questões que mais têm preocupado os países ${ }^{23}$, mesmo que as forças armadas não tenham sido empregadas em seu combate - como o faz a Colômbia - há operações nas quais elas são empregadas em face de sua logística e treinamento ${ }^{24}$.

Pelo discorrido acima, infere-se que às forças armadas cabe, cada vez mais e de maneira mais abrangente em termos de quantidade de países, missões não primárias. Battaglino (20I5) considera que na Argentina deu-se uma expansão baixa e supervisionada, portanto, com um nível de controle civil alto e com baixo poder político dos militares; no caso do Brasil o nível de controle civil é baixo, mas com uma expansão média e com supervisão civil incipiente, o que deixa o poder político dos militares alto. Infere-se, portanto, que tampouco a convergência do papel dos militares ou suas missões foram alcançadas em decorrência da não definição ou limitação dos temas de segurança interna e defesa nacional.

O CEED no Informe Preliminar (20I4) destaca que "os objetivos de uma possível conformação de um sistema de defesa sub-regional [grifo no original], estão vinculados a caracterização e hierarquização de ameaças e riscos de dimensões e impactos regionais, que requerem cooperação e ação conjunta dos países para enfrentá-los de forma coletiva25" (CEED 20I4 - tradução nossa). Reconhece que os temas clássicos de defesa encontram maior coincidência entre os Estados e que em relação às definições de segurança pública residem as maiores discrepâncias, às quais insta sejam sanadas mediante processos de revisão e redefinição das políticas e sistemas de segurança, mas também de defesa.

o ministro da Defesa Raul Jungmann ressaltou a necessidade de os países da região incrementarem a cooperação regional nas fronteiras como modo preventivo de combater crimes transnacionais. Disponível em <http://www.defesanet.com.br/defesa/noticia/23783/XII-CMDA--Ministro-Jugmann-defende-cooperacao-regional-nas-fronteiras-/. Acesso em 25 fev $20 \mathrm{I} 8$.

23 Conforme os documentos das consultas realizadas pela OEA quando da discussão dos mecanismos de segurança hemisférica, que culminaram na Declaração de Segurança das Américas, de 2003.

24 Apenas Chile e Uruguai não preveem o uso das forças armadas para tais operações (ATLAS 2014).

25 No original: "Los objetivos de la posible conformación de un sistema de defensa sub-regional, están vinculados a la caracterización y jerarquización de las amenazas y riesgos de dimensiones e impacto regionales, que requierem de una cooperación y ación de los países para enfrentarlos en forma colectiva". 
Enquanto os temas clássicos de defesa já estão consolidados e os países, além de se defrontarem há mais tempo com os mesmos, encontram-se em um momento em que eventuais discrepâncias têm menos espaço para se desenvolverem por conta da não iminência ou, pelo menos, da baixa probabilidade de se consolidar uma ameaça nestes termos, a segurança foi impactada pelo forte crescimento da presença de atores não estatais e das dinâmicas transnacionalizadas que daí decorrem.

\section{Considerações finais}

Ao longo do tempo os países da chamada América Latina e, mais recentemente os países que compõem o subcontinente da América do Sul, buscaram integrar-se de maneira bastante ampla, alcançando, inclusive, a área de defesa mais recentemente. Se ao longo do século XX a integração não alcançou as condições para se consolidar, no início do século XXI as condições do sistema internacional pareciam convergir para um cenário que permitiria uma aproximação mais definitiva.

Além disso, havia uma convergência regional de diversos governos demonstrando a vontade de aproximação e formação de consensos. Mesmo que não se pudesse descaracterizar completamente seu paradoxo histórico de região com estabilidade externa e instabilidade interna (Medeiros Filho 20I0), o fortalecimento da confiança avançava positivamente, especialmente na sub-região do Cone Sul, mas também, em alguma medida, na porção norte-andina da América do Sul. Com as proximidades ideológicas de diversos líderes políticos, a formação de um mecanismo regional na esfera da defesa sem ser de defesa coletiva - não foi vista com desconfianças e nem com claras intenções de distanciamento dos Estados Unidos, antes disso, promovendo um distanciamento relativo.

O Brasil adotava uma postura de proximidade com seus vizinhos sul-americanos - em um momento de ênfase às regionalidades ${ }^{26}$-, agia no sentido de consolidar sua posição internacional de país emergente, e de potência média e com capacidade de arregimentar a região, bem como, dava sinais de assumir os custos dos processos de aproximação. Promotor do diálogo político, de busca pela multilateralidade - a partir de um discurso que propagava uma multipolaridade cooperativa, como destacado no Livro Branco de Defesa de 20I2, - o país demonstrava o protagonismo da América do Sul em sua política externa e a prioridade que a região tinha em suas relações internacionais.

26 Especialmente no que tange a este trabalho Buzan e Waever (2003), mas também Adler e Barnett (I998). 
A criação do CDS sem identificar adversários comuns, sem almejar ser um órgão de defesa coletiva, mas visando consolidar a região como uma zona de paz, criar uma identidade sul-americana em defesa e criar consensos para o fortalecimento da cooperação regional em defesa, porque decorrente da possibilidade de aproximação que se descortinou após a mudança de relacionamento baseado em projeção de poder entre Brasil e Argentina ainda no final do século XX, mostrava que naquele ex-complexo conflituoso agora se colocavam as condições para pensar a identidade em defesa.

Contudo, ao longo deste tempo os avanços consensuais não permitiram a incorporação de políticas regionais conjuntas. Em países com traços marcadamente soberanistas e que formaram uma instituição com estrutura minimalista (Medeiros, Teixeira Júnior e Reis 20I7), a forma intergovernamental do CDS impede um caráter mais abrangente em sua condução.

Outro desafio regional institucional encontra-se na não superação dos contenciosos fronteiriços, especialmente na região norte. O que demonstra que ainda não é possível pensar em uma região que possa convergir em termos de defesa. Note-se que mesmo que esses contenciosos não estejam completamente resolvidos, eles apresentam uma baixa securitização, mas permanecem latentes. Entretanto parece ser lícito dizer que são pouco securitizados - como nos exemplos de Colômbia e Venezuela - mais devido às situações internas de cada um desses países do que propriamente resultante dos constrangimentos decorrentes da institucionalização regional. Villa $(2017,95)$ mostra o hibridismo da governança em segurança na América Latina, ao asseverar que na região se mantém lado a lado a lógica do balanço de poder e da comunidade de segurança, e estas condições impactam tanto dentro da região, quanto nos países individualmente, motivando ou constrangendo comportamento militarizados.

O entendimento amplo e abrangente de segurança ou o conceito de segurança multidimensional estabelecido em $2002^{27}$ no âmbito da OEA deixa, por um lado, um espaço aberto acerca do que se entende por segurança e, da mesma maneira, por defesa; mas, por outro, dada tal amplitude dos temas, resulta em restrições ante a possibilidade de coordenação de políticas.

O Brasil desempenha o papel de ator chave para o desenvolvimento das relações de defesa e segurança na região, entretanto, depois do seu

27 “...reconhecem que as ameaças, preocupações e outros desafios à segurança no contexto hemisférico de naturezas diversas e alcance multidimensional, e que o conceito e a abordagem tradicionais devem aplicar-se para englobar ameaças novas e não-tradicionais, que abrangem aspectos políticos, econômicos, sociais, de saúde e ambientais", conforme Declaração de Bridgetown: Abordagem Multidimensional à Segurança Hemisférica. Disponível em http://www. oas.org/juridico/portuguese/ 2002/agdec27.htm. 
protagonismo na criação destas instituições e de uma posição bastante definida sobre a região ser um espaço importante na busca por uma inserção internacional proeminente e autônoma do país no mundo, nos últimos anos este protagonismo foi deixado de lado. A política externa brasileira não deu sequência a atuação proativa que resultou na formação desse arcabouço institucional sul-americano.

Uma questão bastante expressiva a considerar é que as características westfalianas são bastante expressivas na região onde os países tradicionalmente são mais e frequentemente impactados por questões internas, voltando-se para dentro de maneira bastante frequente. Esse fator é bastante preponderante atualmente onde o Brasil desempenha um baixo perfil de política externa pois volta-se aos seus próprios problemas de governabilidade e representatividade política, deixando pouco ou quase nenhum espaço para a continuidade da implementação das políticas voltadas aos arranjos regionais. Neste sentido, a Unasul, como projeto político, deixou de ser uma prioridade ao Brasil. A Venezuela, por seu turno, com graves dificuldades econômicas e contestações sociais e políticas enfrentadas pelo governo de Nicolás Maduro, não tem contado com apoio regional para a resolução da situação social e econômica preocupante que o país tem enfrentado.

No mesmo sentido, ao se observar os novos documentos de defesa constata-se que o Brasil negligencia a América do Sul ao não dar destaque à Unasul como projeto político, o que deixa transparecer que o país, como força motriz da institucionalização regional, não mantém uma linearidade e, em alguma medida, a sua atual conduta se dissocia da política de construir uma visão comum em matéria de defesa e gerar consensos para fortalecer a cooperação regional nesta área.

Diante destas condições, pode-se ponderar acerca de alguns cenários característicos para o futuro das relações de segurança e defesa na região, no primeiro deles, em um contexto internacional de ampliação de espaços multilaterais, a região poderá continuar investindo institucionalmente visando aprofundar acordos de cooperação em defesa e solidificando o espaço regional para sua inserção internacional. Por outro lado, se o Brasil se mantiver com baixo perfil de política externa em decorrência da manutenção e/ou aprofundamento da instabilidade interna econômica e política - o que acarretará sérios custos institucionais regionais - a aproximação regional será bastante pontual, avançando apenas algumas relações bilaterais, pendendo fortemente para o uso seletivo da institucionalização regional.

As visões de concertação capitaneadas em medidas como a formação de confiança mútua, especialmente para criar regras para as compras militares, e para a formação e a capacitação militar, têm sido desenvolvidas no 
sentido de uma visão cooperativa, respeitando a coexistência de distintas definições políticas e conceituais sobre defesa e segurança. Esse resguardo à coexistência de distintas definições produz um impacto significativo em relação aos limites que a possibilidade de convergências vai apresentar.

Os empregos distintos das forças armadas, como se denotou na seção anterior, é consequência bastante direta tanto da confusão entre segurança pública e defesa, quanto da imprecisa e ampla definição de segurança. Se as constituições nacionais são menos declaratórias neste sentido, as legislações infraconstitucionais - na maior parte dos países - é que define tais ações. $\mathrm{Na}$ falta de fortalecimento dos instrumentos de segurança pública interna, mesmo com crescentes níveis de insegurança decorrentes da violência, mas também do tráfico de drogas e armas, a solução tem-se apresentado como ambígua: não se alcançou a convergência das missões das forças armadas, tampouco se instrumentalizou uma possível mudança, mas o caráter de suas ações é cada vez mais de segurança do que de defesa. Essa característica, contudo, não chega a ser uma inovação na região pois o combate à subversão interna foi, durante muito tempo, uma sua atuação. Mesmo a criação do CDS só teve efeitos limitados na geração de uma agenda positiva o suficiente para coordenar assuntos e perspectivas de ação em defesa.

Os resultados da aproximação com o CDS não foram suficientes para modificar os padrões de relacionamento bilaterais, pois a ambiguidade - especialmente ao não definir precisamente os temas de segurança e defesa -, e a complexidade das relações regionais não desapareceram. Os custos da operacionalização regional se mantêm e mesmo que se tenha avançado nos níveis de concertação e confiança, estes não são lineares para todos os países sul-americanos.

\section{REFERÊNCIAS}

Adler, Emanuel and Michael Barnett, eds. I988. Security Communities. Cambridge: Cambridge University Press.

Aguilar, Sérgio L. C. 2008. "Políticas de Defesa e Orçamentos Militares no Cone Sul." In Defesa, Segurança Internacional e Forças Armadas: textos selecionados do Primeiro Encontro da Associação Brasileira de Estudos de Defesa, organized by Maria Celina D’araújo, Samuel A Soares and Suzeley K. Mathias, IOI-I2I. Ied. Campinas: Mercado de Letras.

Battaglino, Jorge. 2009. "O Brasil e a criação do Conselho de Defesa Sul-Americano: uma convergência de vantagens”, Revista Nueva Sociedad (Dezembro): 79-89. 
Battaglino, Jorge. 2015. "Políticos y Militares en los gobiernos de la nueva izquierda sudamericana". Política y Gobierno XXII: 3-43.

Brasil. 20I2. Livro Branco de Defesa Nacional. Accessed September I2, 2017. http://www.defesa.gov.br/arquivos/2012/meso7/lbdn.pdf.

Buzan, Barry and Ole Waever. 2003. Regions and Powers: the structure of international security. Cambridge: Cambridge University Press.

Cardoso, Fernando Henrique. I996. "Discurso na cerimônia de anúncio da política de defesa nacional I996". Acessed September I2, 20I7. http:// www.biblioteca.presidencia.gov.br/presidencia/ex-presidentes/fernando-henrique-cardoso/discursos/Io-mandato/.

Centro de Estúdios Estratégicos de la Defensa (CEED). 20I2. Conselho de Defesa Sul-Americano. "Registro Suramericano de gasto de defensa". Accessed March I4, 20I5. http://www.ceedcds.org.ar/Portugues/o9-Downloads/PORT-Metodologia_Comun.pdf.

20I4. Conselho de Defesa Sul-Americano. "Informe del CEED al Consejo de Defensa Suramericano acerca de los terminos de referencia para los conceptos de seguridad y defensa em la region suramericana".

. 20I7. Conselho de Defesa Sul-Americano. "Registro Sul-Americano de Gastos Agregados em Defesa 2006-20I5". Edição Especial.

s/d. Conselho de Defesa Sul-Americano. "Formulário Padronizado de Remessa de Informação".

Cepik, Marco. 2009. "Segurança nacional e cooperação Sul-Sul: Índia, África do Sul e Brasil. In Brasil, Índia e África do Sul: desafios e oportunidades para novas parcerias, organized by Maria Regina Soares de Lima and Monica Hirst, 63-II8. São Paulo: Paz e Terra.

Consejo de Defensa Suramericano. 20ıо. "Procedimientos de Aplicación para las Medidas de Fomento de la Confianza y Seguridad". Accessed April 2, 2016 http://www.ceedcds.org.ar/Espanol/ogDownloads/ PROCEDIMIENTOS_MEDIDAS_DE_CONFIANZA_Y_SEGURIDAD.pdf.

. 20I5. Centro de Estudos Estratégicos. "Institucionalidade da Defesa na América do Sul”. Accessed April 2, 20I6. http://www.ceedcds.org.ar/Portugues/og-Downloads/INST-DEF-PORT.pdf.

Diamint, Rut. 2006. Misiones militares. "Respondiendo a las tensiones del sistema internacional”. In La Seguridad desde las Dos Orillas. Un debate entre Europa y Latinoamerica, edited by Rafael Martinez and Jo- 
seph Tulchin, 59-78. Barcelona: Fundació CIDOB.

Donadio, Marcela. 2003. “Las Relaciones Cívico-Militares y la Construcción de Instituciones en América Latina: enfrentando las crisis de las jóvenes democracias". RESDAL - Red de Seguridad y Defensa de América Latina.

Donadio, Marcela. 20Io. "El Consejo de Defensa Suramericano y su papel en el desarrollo de confianza mutua". In: CDS-UNASUR. Presidencia Pro Tempore Ecuador. Confianza y Seguridad en América del Sul. Cuadernos de Defensa N.2. Publicación del Consejo de Defensa Suramericano.

Donadio, Marcela. 20II. "Visões estratégicas na América do Sul". In Comparando a Defesa Sul-Americana, organized by Marcos Aurelio G. de Oliveira, III-I26. Recife: Editora Universitária da UFPE.

Donadio, Marcela and María de la Paz Tibiletti. 20I4. Atlas Comparativo de la Defensa en América Latina y Caribe. Ciudad Autónoma de Buenos Aires: RESDAL.

Donadio, Marcela and Samanta Kussrow. 20I6. Atlas Comparativo de la Defensa en América Latina y Caribe. Ciudad Autónoma de Buenos Aires: RESDAL.

Flemes, Daniel. 2005. "Notas teóricas sobre a formação de uma comunidade de segurança entre a Argentina, o Brasil e o Chile". Revista Sociologia Política 24: 2I7-23I.

Flemes, Daniel and Michael Radseck. 2009. "Creating Multilevel Security Governance in South America”. Giga Working Paper II7.

Garcia, Jaime. 2002. "El Militar Postmoderno en América Latina". Security and Defense Studies Review 2 (Summer).

Gratius, Susanne. 2007. "O Brasil nas Américas: potência regional pacificadora?” Working Paper: Fundación para las Relaciones Internacionales y el Diálogo Exterior (FRIDE), Madrid, 35.

Heegaard, William. 20ıo. "El camino largo de integración regional de defensa y seguridad: desafíos y potencialidades del Consejo de Defensa Suramericano". Independent Study Project (ISP) Colletion. Paper I238.

Latinobarometro. "Corporación Latinobarómetro Informe 2016". Accessed September I7, 20I7. http://www.latinobarometro.org.

Medeiros, Marcelo de A., Augusto Wagner M. Teixeira Jr. And Elton G. dos Reis. 20I7. "Cooperação para autonomia? Explicando o paradoxo da política externa brasileira para a Unasul”. Revista de Sociologia e Política, 6r: 97-г23. 
Medeiros Filho, Oscar. 20Io. Entre a cooperação e a dissuasão: políticas de defesa e percepções militares na América do Sul. Doctoral thesis (Doutorado em Ciência Política) - Universidade de São Paulo, São Paulo.

Nolte, Detlef. 2018. "Cost and Benefits of Overlapping Regional Organizations in Latin America: The Case of the OAS and UNASUR". Latin American Politics and Society, no. 60 (February): I28-I53.

Pagliari, Graciela De Conti. 20ı6. "Forças armadas e sua importância para a região austral do Prata". In Fronteiras contemporâneas comparadas: relações internacionais e segurança regional no Brasil e na União Europeia, organized by Maria Raquel Freire, Danielle J. Ayres Pinto and Daniel Chaves. Macapá: UNIFAP.

Rojas Aravena, Francisco. 1996. "Medidas de confianza mutua y balance estratégico: un vínculo hacia la distensión y la estabilidad". In Balance estratégico y medidas de confianza mutua, edited by Francisco Rojas Aravena, 3I-54. Santiago: FLACSO-Chile.

Saint-Pierre, Héctor L. and Alberto Montoya C. Palacios Júnior. 20I4. "As medidas de confiança no Conselho de Defesa Sul-Americano (CDS): análise dos gastos em Defesa (2009-20I2)". Revista Brasileira de Politica Internacional, no. 57: 22-39.

Saint-Pierre, Héctor L. and Laura M. Donadelli. 2016. "As atribuições das forças armadas nos países Sul-Americanos". In Defesa e segurança do Atlântico Sul: VIII ENABED, organized by Érica C. A. Winand, Thiago Rodrigues and Sérgio Aquilar, 87-I04. São Cristóvão: Editora UFS.

Serbin, Andrés. 2009. "A América do Sul em um mundo multipolar. A Unasul é a alternativa?” Nueva Sociedad (December).

Soares de Lima, Maria Regina. 20ıo. "Diplomacia, defesa e a definição política dos objetivos internacionais: o caso brasileiro". In Segurança Internacional - Perspectivas Brasileiras, edited by Nelson Jobim, Sergio W. Etchegoyen and João Paulo Alsina. Rio de Janeiro: Ed. FGV.

UNASUR. "Estatuto do Conselho de Defesa Sul-Americano da UNASUL". Accessed March I7, 2015. http://www.ceedcds.org.ar/Portugues/o9Downloads/PORT-ESTATUTO_CDS.pdf.

Villa, Rafael D. and Manuela T. Viana. 20ıo. “Security issues during Lula's administration: from the reactive to the assertive approach". Revista Brasileira de Política Internacional, (special edition) no. 53: 9I-II4.

Villa, Rafael D. and Milton C. Bragatti. 20I5. "Complexificação das Instituições de defesa na América do Sul”. Carta Internacional, ed. especial, IO: 4-22. 
Villa, Rafael D. 20I7a."Brazilian Hybrid Security in South America”. Revista Brasileira de Política Internacional, v. 60, no. 2: I-22.

Villa, Rafael D. 20I7b. "Security Community or Balance of Power? Hybrid Security Governance in Latin America". In Power dynamics and security in Latin America, edited by Marcial A. G. Suarez, Rafael D. Villa and Brigitte Weiffen. London: Palgrave Macmillan.

\section{RESUMO}

Investiga-se a aproximação em defesa e segurança na América do Sul. A hipótese testada considera que estes países somente tendem a aproximação na medida em que os seus custos estão menos atrelados à mudança de suas políticas individuais propondo-se, dessa forma, a consensos superficiais em detrimento da incorporação de políticas conjuntas. Para tanto, centra-se a análise nas medidas de confiança relativamente aos gastos militares adotadas desde a criação do CDS, bem como as atribuições das forças armadas para verificar se - no caso daquelas - as medidas serviram para fortalecer as confluências em defesa, e - no caso destas - se, em face dos apontados problemas comuns de defesa, as atribuições têm convergido.

\section{PALAVRAS-CHAVE}

América do Sul; Conselho de Defesa Sul-Americano; segurança e defesa 